\title{
Chemical Analysis of Karenia papilionacea
}

2 Nicholas Fowler $^{\mathrm{a}^{*}}$, Carmelo Tomas $^{\mathrm{a}}$, Daniel Baden ${ }^{\mathrm{a}}$, Lisa Campbell ${ }^{\mathrm{b}}$, Andrea Bourdelais ${ }^{\mathrm{a}}$

3 University of North Carolina, Center of Marine Science, Wilmington, NC 28409 USA

4 Nlf7589@uncw.edu; Tomasc@uncw.edu; Baden@uncw.edu; Bourdelaisa@uncw.edu

$5 \quad{ }^{\mathrm{b}}$ Texas A\&M Univ, Dept Biol, College Stn, TX 77843 USA

$6 \quad$ Lisacampbell@tamu.edu

$7 \quad *$ Corresponding author. Email address: Nlf7589@uncw.edu

8

9

10 One of the most widely studied organisms responsible for Harmful Algal Blooms (HABs) is the

11 marine dinoflagellate Karenia brevis. This organism produces neurotoxic compounds known as

12 brevetoxins. A related dinoflagellate, Karenia papilionacea, has been reported to occasionally

13 co-bloom with Karenia brevis but has received little attention as a possible toxin producing

14 species. Therefore, our aim was to investigate the toxin profile for K. papilionacea. A toxic

15 fraction was identified using a cell based cytotoxicity assay and the toxin was isolated and

16 identified as the ladder frame polyether brevetoxin-2 (PbTx-2) using mass spectrometry (MS)

17 and nuclear magnetic resonance (NMR). Toxin production in K. papilionacea increased in

18 response to hypoosmotic stress, as previously observed in K. brevis.

19 Keywords: Karenia papilionacea, Karenia brevis, brevetoxin, toxin isolation, HAB, osmotic

20 stress

21 


\section{1. Introduction}

23 Although most HAB events are comprised of a single dominant algal species, there is

24 often more than one species of algae present during a single event. For instance, Karenia brevis

25 blooms generally contain $K$. brevis as the dominant species but other Karenia species such as $K$.

26 mikimotoi are also found in significant numbers (Heil \& Steidinger 2009). Often, the toxicity of

27 a bloom is associated with a single HAB species, however, at times there may be additional

28 species present for which very little is known, including their toxicity. This is especially notable

29 for the dinoflagellate Karenia papilionacea, that is known to co-occur with K. brevis during

30 HAB events and has also been associated with toxic blooms in the absence of $K$. brevis (McNabb

31 et al. 2006).

32 Karenia papilionacea has two different cell forms, a large and small cell (Figure 1). Both

33 are very similar to $K$. brevis and have been observed in the same bloom. The larger butterfly

34 form has a pronounced hypothecal excavation (Haywood et al. 2004) and has been shown to

35 contract horizontally allowing the left and right sides to almost touch, similar to a butterfly

36 flapping its wings. The smaller cell form has a slight hypothecal excavation making it look very

37 similar to K. brevis (Haywood et al. 2004) (Figure 1). In fact, until K. papilionacea was formally

38 identified as a separate species in 2004 (Haywood et al. 2004), it was often mistakenly identified

39 as K. brevis. There are early reports of a 'butterfly' shaped K. brevis species (Steidinger 1979)

40 which is now thought to actually have been $K$. papilionacea. K. papilionacea has been reported

41 to be able to change cell shape quickly when under stressed growth conditions (Gómez, 2006).

42 Compared to many marine dinoflagellates, $K$. papilionacea has a wide distribution. $K$.

43 papilionacea is a neritic species also found in oceanic gyre systems (Gómez, 2006). Although, it 
44 is most commonly found in coastal New Zealand waters, it has also been observed in the Gulf of

45 Mexico, Florida Straits, Delaware Bay, Mediterranean, North Atlantic, South China Sea, and the

46 Caribbean Sea.

$47 \quad$ Figure 1: Comparison of K. papilionacea cellular morphologies to K. brevis.

48
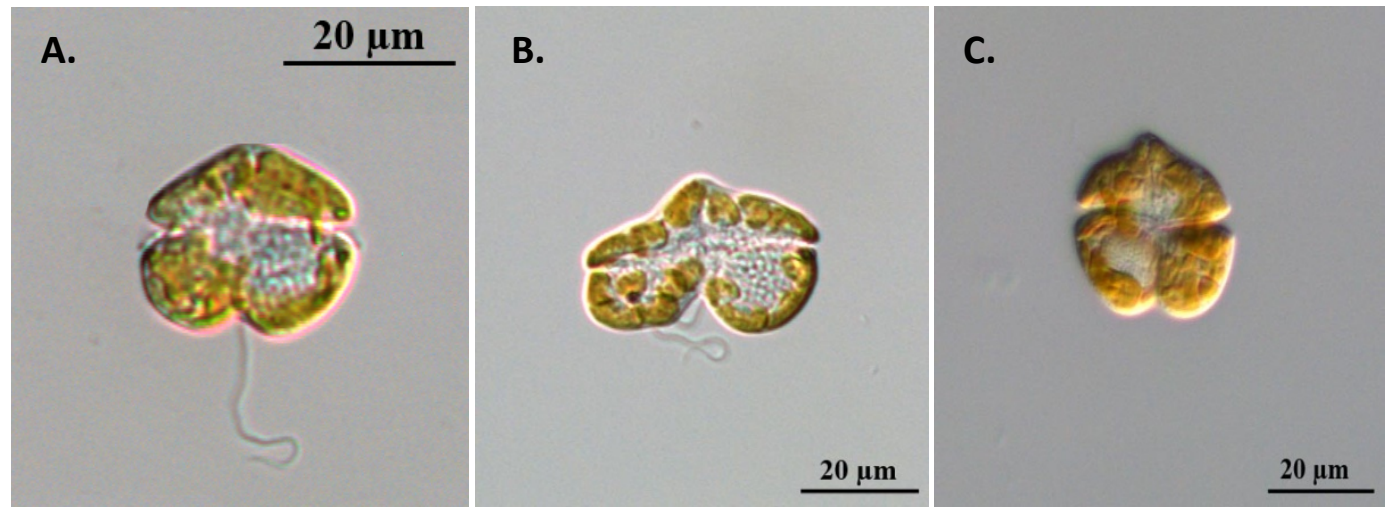

50

51 Fig. 1: Comparison of two cellular morphologies to K. brevis. A. K. papilionacea, K. brevis-like form; B. K.

52 papilionacea butterfly form; C. K. brevis.

53

$54 \quad$ To date, all Karenia species that have been studied in depth have been associated with

55 fish kills and marine mammal mortality, which supports the designation as a toxic genus. For

56 example, K. brevis produces a family of ladder frame polyethers known as brevetoxins (Baden et

57 al. 1979, Lin 1981)), Karenia selliformis produces the neurotoxin gymnodimine (Seki et al.

58 1995), Karenia mikimotoi produces ladder frame polyethers called gymnocins (Satake et al 2002,

59 Satake et al. 2005), and Karenia brevisulcata produces Karenia brevisulcata toxins (KBT) and

60 brevisulcata acids (BSX) (Holland et al. 2012). K. papilionacea, K. umbella, and K. bidigitata

61 are considered to be toxic but the toxins associated with each species are yet to be identified

62 (Brand et al. 2012). 
64 brevis and $K$. papilionacea are often found in the same bloom. During toxic events that contain

65 both $K$. brevis and K. papilionacea, the toxicity has generally been attributed to K. brevis

66 because it is known to produce brevetoxins. However, in blooms that were composed primarily

67 of $K$. papilionacea in the absence of $K$. brevis, brevetoxins $(50-110 \mathrm{pg} / \mathrm{mL})$ were detected

68 using an ELISA with antibodies specific for brevetoxins containing the PbTx-2 backbone. Toxin

69 isolation and characterization was not done for samples from this bloom (Haywood et al. 2004).

70 Toxin identification was not confirmed by liquid chromatography-mass spectrometry (LC/MS)

71 either. More recently, blooms of K. papilionacea in New Zealand and K. umbella in Tasmania,

72 Australia, have been associated with salmonid aquaculture mortality (de Salas et al. 2004). These

73 blooms consisted of several different Karenia species and showed the presence of several toxins.

74 Due to the complex species profile of most blooms attributing a particular toxin to one species

75 has been difficult. For example, brevetoxins, gymnodimine and domoic acid were isolated from

76 shellfish from the 1992-1993 biotoxin event in New Zealand (Landsberg 2002, Seki et al. 1995,

77 1996, Mackenzie et al. 1996, Chang et al. 1995, Rhodes et al. 1996). There were numerous

78 Karenia species present, all initially identified as K. brevis (Chang et al. 1995, Haywood et al.

79 1996) but later reclassified as several new species (Haywood et al. 2004). One of these newly

80 described species could be responsible for the production of one or many of these toxins

$81 \quad$ Brand et al. (2012) reported that both Mass Spectrometry (MS) and Nuclear Magnetic

82 Resonance (NMR) techniques are essential to confirm toxin identity in a bloom. These two

83 methods have become the standard for identifying and characterizing new toxins. Harwood et al.

84 (2014) recently used these techniques to quantify and create a sensitive detection assay for the

85 recently described brevisculatic acids (BSXs) and brevisculcenals (KBTs) from the toxic 
86 dinoflagellate $K$. brevisculata. Mooney et al. (2007) reported that K. papilionacea, along with

87 other Karenia species, produces unusual lipids, sterols, and PUFAs that have been shown to be

88 ichthyotoxic. Research by Chang (2011) showed that K. brevis and other Karenia species (K.

89 concordia, K. brevisulcata, K. mikimotoi) produce unidentified allelochemical compounds that

90 can suppress the growth of most other species of algae, such as raphidophytes, diatoms and other

91 photosynthetic organisms but are not effective against other dinoflagellates. Mooney et al.

92 (2007) reported K. papilionacea showed high levels of 23-methyl-27-norergosta-8(14), 22- dien-

93 3b-ol (59\%-66\%), and an unknown C28 sterol with three double bonds (Trimethylsilyl ether

94 MW 468, 16\%-17\%). These compounds were shown to be present with a suite of other,

95 unknown, C28 unsaturated sterols. Although, K. papilionacea has been associated with toxic

96 blooms and fish kills no toxin has been identified from mono-blooms or cultures of this species.

97 The current study is designed to determine the in vitro cytotoxicity of $K$. papilionacea using

98 bioassay guided fractionation of $K$. papilionacea extract and subsequent identification of the

99 toxin(s) produced by K. papilionacea using a combination LC/MS and NMR experiments.

100 2. Materials and Methods

101 Methanol, acetonitrile, $0.1 \%$ formic acid in acetonitrile, acetone, and ethyl acetate were

102 purchased from Honeywell Burdick and Jackson (Muskegon, MI). Petroleum ether and

103 molecular grade ethanol were purchased from Fisher Scientific (Fair Lawn, NJ). Chloroform was

104 purchased from Mallinckrodt Chemicals (Phillipsburg, NJ). Sodium nitrate, sodium phosphate,

105 disodium salt dihydrate, ferric chloride, boric acid, manganese chloride, cobalt chloride, and

106 thiamine hydrochloride were purchased from Fisher Scientific (Fair Lawn, NJ). Tetra

107 deuteromethanol, sodium selenite, cyanocobalamin (vitamin $\mathrm{B}_{12}$ ), and biotin (vitamin $\mathrm{H}$ ) were 
108 purchased from Sigma-Aldrich (St. Louis, MO) and the zinc chloride was purchased from

109 Mallinckrodt Chemicals (Phillipsburg, NJ).

$110 \quad 2.1$ Culture

111

K. papilionacea, (CAWD-9 (Cawthron Micro-Algae Collection, Hawkes Bay, New

112 Zealand) and (KP-0709-2) Rehoboth Bay, Delaware) were grown in LH media for 4 weeks in a

$11310 \mathrm{~L}$ bioreactor (IKA Works, Wilmington, NC) at $22^{\circ} \mathrm{C}$ with $16 \mathrm{hr}$ light/ $/ 8 \mathrm{hr}$ dark light regiment.

114 The LH media was composed of L1 media using filtered sea water (Guillard and Hargraves

$1151993)$ with a $50 \%$ PII metal mix $\left(\mathrm{Na}_{2} \mathrm{EDTA}, 2 \mathrm{H}_{2} \mathrm{O}-6 \mathrm{~g} ; \mathrm{FeCl}_{3}, 6 \mathrm{H}_{2} \mathrm{O}-.290 \mathrm{~g} ; \mathrm{H}_{3} \mathrm{BO}_{3}-6.850 \mathrm{~g}\right.$;

$116 \mathrm{MnCl}_{2}, 4 \mathrm{H}_{2} \mathrm{O} ; \mathrm{ZnCl}_{2}-.060 \mathrm{~g} ; \mathrm{CoCl}_{2}, 6 \mathrm{H}_{2} \mathrm{O}-.026 \mathrm{~g}$ ) with the addition of sodium selenite, $.01 \mu \mathrm{M}$

117 (Loeblich 1975; Haywood et al. 2004). These alterations were referred to by Tatters et al. (2010)

118 as a modified L1 media but have since been renamed LH media. The seawater was collected

119 from the Gulf Stream near Wilmington, NC and transported back to the culture facility to be

120 filtered using a Whatman GF/F paper filter (Buckinghamshire, UK). The salinity of the seawater

121 was adjusted to a salinity of 31 by adding filtered deionized freshwater to filtered seawater prior

122 to nutrient addition. After preparation, the LH media was inoculated with approximately 100,000

$123 \mathrm{cell} / \mathrm{L}$ from the stock cultures of $K$. papilionacea. Cell counts using $5 \mathrm{ml}$ of culture from the

124 bioreactor were conducted using the Utermöhl method, (Utermöhl 1931) and were monitored

125 and recorded every 3-4 days from time of inoculation until the culture reached senescence, at

126 which point, it was harvested.

\section{$127 \quad 2.2$ Culture Extraction}

128 The K. papilionacea cultures were extracted using a chloroform:water extraction

129 technique as described by Baden and Mende (1982). Particulate matter was removed from the 
130 chloroform extract by filtration using Whatman 542 paper filter (185mm, Buckinghamshire, UK)

131 and Celite 545 (EMD Chemicals, Gibbstown, NJ). After filtration through the Celite, the extract

132 was dried under vacuum and resuspended in $100 \mathrm{ml}$ ethyl acetate. The ethyl acetate solution was

133 washed with water $(3 \times 100 \mathrm{~mL})$ and separated. The combined aqueous extracts were

134 backwashed with fresh ethyl acetate to recover any residual lipophilic material. The ethyl acetate

135 layers were collected and dried down with a rotor evaporator (RV10 with HB10 digital water

136 bath, IKA works, Wilmington, NC). The residue obtained from the ethyl acetate extracts was

137 further partitioned based on polarity using a petroleum ether $/ \mathrm{MeOH} / \mathrm{H}_{2} \mathrm{O}(50: 40: 10$, v/v/v)

138 mixture (Truxal et al. 2010). The $\mathrm{MeOH} / \mathrm{H}_{2} \mathrm{O}$ layer was collected and dried under vacuum and

139 used for the following experiments.

$140 \quad$ 2.3 Fractionation of the $K$. papilionacea Extract for Cytotoxicity Studies

141 Prior to the cytotoxcicity studies the methanol extract was filtered through a 0.2 micron

142 polypropylene filter (Whatman, Buckinghamshire, UK) and then dried under vacuum. The

143 filtrate was the redissolved in 90\% acetonitrile and 10\% water and separated using High

144 Performance Liquid Chromatography (HPLC). The solvent delivery system was composed of a 145 Shimadzu Scientific Instruments HPLC consisting of 2 LC-10AS Liquid handling pumps, a

146 SCL-10A System Controller, and SPD-10AVUV-VIS Dectector. The HPLC conditions for the

147 initial HPLC separation were achieved using a Phenomenex Phenyl-Hexyl column, $5 \square \mathrm{M}, 100$

148 A, $8 \times 250 \mathrm{mM}$ reversed-phase column at a flow rate of $3.4 \mathrm{~mL} / \mathrm{min}$. A binary gradient starting

149 at 50\% MPA proceeding to $0 \%$ MPA over 45 minutes was used, MPA (100\% water), MPB

$150(100 \% \mathrm{MeOH})$. Fractions were separated into 45 one minute fractions using a Foxy Jr. Fraction

151 collector (ISCO, Lincoln, NE). The collected fractions were put into scintillation vials and dried 
152 using a Speed-Vac (Savant Instruments, Speed VacPlus SC210A and Refrigerated Vapor Trap, 153 Holbrook, NY).

\section{$154 \quad 2.4$ Cytotoxicity Assay}

155 SJCRH30 cells (ATCC, Manassas, VA) were seeded at a density of 5,000 cells/well in

156 Greiner CELLcoat poly-D-lysine-coated $96-$ well plates and incubated at $37^{\circ} \mathrm{C}$ overnight. The

157 following day, cells were treated with $1 \square 1$ of sample fractions suspended in $1 \mathrm{ml}$ of ethanol and

158 cell nuclei were stained with a $0.1 \square \mathrm{g} / \mathrm{ml}$ final concentration of Hoechst 33342 (Invitrogen) that

159 was added to the sample/medium solution (RPMI 1640 supplemented with 10\% FBS) and 160 incubated at $37^{\circ} \mathrm{C}$ for $48 \mathrm{hrs}$.

161 After incubation the growth medium containing the Hoechst dye and fraction was

162 removed from the wells, and the cells rinsed once with warm HBSS (100 $\square 1$ per well). The

163 HBSS rinse was replaced with warmed $200 \mathrm{nM}$ TT488 staining solution (200 nM TT488 in

164 HBSS, $100 \square 1$ per well) to stain the microtubules. The plate was then returned to the $37^{\circ} \mathrm{C}$

165 incubator for 30 minutes before imaging on an Image Xpress Micro system equipped with an

166 environmental control chamber warmed to $37^{\circ} \mathrm{C}$. Hoechst 33342 and TT488 staining was

167 visualized using a DAPI filter and an FITC filter, respectively. Transmitted light images were

168 also collected to assess cell morphology.

169 Cytotoxicity of each fraction was determined using the ImageXpress Micro (Molecular

170 Devices, Sunnyvale, CA) using the multi-wavelength cell scoring macro. For this macro the

171 number of nuclei, cell size, and cell count for each well was determined. Fractions with

172 differences of more than $30 \%$ from the control wells were chosen for further purification.

\section{$173 \quad 2.5$ Purification Techniques}


175 assay using a reverse-phased HPLC Prontosil 200-5 C30, 8.0 x 250mm (Bischoff

176 Chromatography, Leonberg Germany) or a microsorb-MV 100-5 C18, 250 x 4.6mm from Varian

177 (Walnut Creek, CA) column using a isocratic mobile phase (ACN or $\mathrm{MeOH}$ ) and collected by 178 hand.

\section{$179 \quad 2.6$ Mass Spectrometry}

181 Sciex Q Trap 2000 MC/MS/MS system, Turbo spray @ 300 C. The experiment was a Q1 MS, 182 positive ion mode with a sweep width of 110.0 - $1700.0 \mathrm{amu}$ (ionization parameters: curtain gas:

$18325.0 \mathrm{psi}$; temperature: $300.0{ }^{\circ} \mathrm{C}$; ion source gas 1: $35.0 \mathrm{psi}$; ion source gas 2: $30.0 \mathrm{psi}$; interface

184 heater: on; ion spray voltage: $4500.0 \mathrm{~V}$; declustering potential: $100.0 \mathrm{~V}$; entrance potential: 11.0

$185 \mathrm{~V})$. Three $\square \mathrm{L}$ of sample was injected into the Qtrap using an Agilent 1100 series G1312A

186 Binary pump, G1313A Autosampler, and G1379A Degasser. The solvent conditions for the 187 HPLC were 20\% mobile phase A isocratic (MPA $\left(98 \% \mathrm{H}_{2} 0,2 \% \mathrm{ACN}, 0.1 \% \mathrm{FA}\right), \mathrm{MPB}(98 \%$

$188 \mathrm{ACN}, 2 \% \mathrm{H} 2 \mathrm{O}, .1 \% \mathrm{FA})$ ), flow rate $110 \square \mathrm{L} / \mathrm{min}$ with a 4 minute run time. Samples were 189 dissolved in a mixture of 50\% acetone:50\% MPB prior to injection.

\subsection{High Resolution Mass spectrometry}

192 Performance Liquid Chromatography-High Resolution Mass Spectrometry (UPLC/HRMS).

193 UPLC/HRMS was performed on an Agilent Infinity 1290 UPLC consisting of a binary pump, a

194 degasser, a diode array detector (lambda $=215)$, thermostatted column compartment $\left(40^{\circ} \mathrm{C}\right)$, and 195 autosampler. The column used for separation was an Agilent Eclipse plus C18 column (1.8 mm, 
2.1 X $50 \mathrm{~mm})$ protected by an EC C18 guard column $(2.7 \mu \mathrm{m}, 2.1 \times 5 \mathrm{~mm})$. An isocratic mobile

197 phase was used consisting of 80:20 v:v (LCMS grade Acetonitrile: HPLC grade H20 + 0.1\%

198 formic acid) with a flow rate of $300 \mu \mathrm{l} / \mathrm{min}$ and a 4 min run time. HRMS of target compounds

199 was performed on a Bruker micrOTOF-Q II HRMS using an Electrospray ionization (ESI)

200 source set in positive mode, dry heater setting of $200 \mathrm{C}$, capillary voltage of $4000 \mathrm{~V}$, nebulizer

201 pressure of $3.0 \mathrm{Bar}$, and drying gas flow of $10.0 \mathrm{l} / \mathrm{min}$. The end plate offset was set to $-500 \mathrm{~V}$,

202 the collision cell RF was set to $60.0 \mathrm{Vpp}$ and the scan with was set from $50 \mathrm{~m} / \mathrm{z}$ to 3000

$203 \mathrm{~m} / \mathrm{z}$. The whole system was run by Hystar 3.2 (Bruker Biospin, Billerica, MA) and the data was

204 processed and analyzed using Compass (Bruker Biospin, Billerica, MA).

\section{$205 \quad 2.8$ NMR}

A Bruker Avance $500 \mathrm{mHz}$ NMR equipped with a $1.7 \mathrm{~mm}$ TXI probe was used for 207 structure elucidation of isolated compounds. The sample was dissolved $100 \mu \mathrm{CD}_{3} \mathrm{OD}$ NMR 208 solvents (Sigma - Aldrich, St. Louis MO). Both 1-D $\left({ }^{1} \mathrm{H}\right.$ and ${ }^{13} \mathrm{C}$ and 2-D spectra ${ }^{1} \mathrm{H}-{ }^{1} \mathrm{H}$ COSY,

$209{ }^{1} \mathrm{H}-{ }^{1} \mathrm{H}$ TOCSY, ${ }^{1} \mathrm{H}-{ }^{13} \mathrm{C}$ HMBC, and ${ }^{1} \mathrm{H}-{ }^{13} \mathrm{C}$ HSQC experiments were performed.

\section{$210 \quad 2.9$ Toxin Production per Cell}

211 1.5L cultures of both strains were grown specifically for the use of determining how

212 much PbTx-2 is produced on a per cell basis. The cultures were extracted in ethyl acetate as

213 mentioned above and the samples were run through a Phenomenex Kinetex 2.6u PFP, 100A, 150

$214 \times 3.00 \mathrm{~mm}$ column on the mass spectrometer using a Multiple Reaction Monitoring (MRM)

215 method in a positive ion mode (ionization parameters: curtain gas: 23.0 psi, temperature: 425.0

$216{ }^{\circ} \mathrm{C}$, ion source gas 1: $30.0 \mathrm{psi}$, ion source gas 2: $75.0 \mathrm{psi}$, interface heater: on, ion spray voltage:

$2175300.0 \mathrm{~V}$, declustering potential: $85.0 \mathrm{~V}$, entrance potential: $11.0 \mathrm{~V}$ ). Four $\mu$ l of sample was 
218 injected into the Qtrap using an Agilent 1100 series G1312A Binary pump, G1313A

219 Autosampler, and G1379A Degasser. The solvent conditions for the HPLC were 40\% MPA from

220.10 to $5 \mathrm{~min}, 1 \%$ MPA from 5.1 to $15 \mathrm{~min}$, and $40 \%$ MPA from 12.1 to $20 \mathrm{~min}$. The flow rate

221 ramped from $110 \mu \mathrm{l} / \mathrm{min}$ (.10 to $5 \mathrm{~min})$ to $140 \mu \mathrm{l} / \mathrm{min}$ (5.1 to $15 \mathrm{~min})$ and back to $110 \mu \mathrm{l} / \mathrm{min}(15.1$

222 to $20 \mathrm{~min}$ ). Retention times for the brevetoxin standards and samples were compared to

223 determine if the correlating mass is a brevetoxin. Brevetoxin standards were created from

224 purified unialgal Karenia brevis (Wilson strain) cultures as previously described (Bourdelais et

225 al., 2005; Truxal et al., 2010). The brevetoxin standards were made by adding 977 ul of MPB to a

$226.0977 \mathrm{mg}$ vial of $\mathrm{PbTx}-2$ to make a concentration of $40,000 \mathrm{pg} / \mu \mathrm{l}$. Serial dilutions were done to

227 create a final concentration of $4 \mathrm{pg} / \mu$ l. These serial dilutions were used to calculate how much

228 toxin was present per injection to be able to calculate the toxin production per cell.

2292.10 Test for Contamination - Raw Culture Samples

230 Given that much of the research conducted within our laboratories is concerned with the

231 culturing and isolation of compounds from K. brevis, it was necessary to ascertain that any toxins

232 associated with $K$. papilionacea were not merely contaminants from the K. brevis research. To

233 ensure that the presence of any toxin was not due to contamination from the laboratory

234 equipment, the use of virgin glassware as well as a series of raw culture samples was taken.

235 Briefly, 25ml of raw culture sample was taken from each carboy and filtered through a $3 \mathrm{ml}$

236 Strata $\mathrm{X}$ column. The column was preconditioned by washing with $10 \mathrm{ml}$ of $\mathrm{MeOH}$, followed by

$23710 \mathrm{ml}$ of $\mathrm{H}_{2} \mathrm{O}$. The $25 \mathrm{ml}$ of culture was then added and washed with $10 \mathrm{ml} \mathrm{of} \mathrm{H}_{2} \mathrm{O}$, followed by

$23820 \mathrm{ml}$ of acetone. The acetone layer was collected and filtered using a 0.2 micron filter

239 (polypropylene, Whatman, Buckinghamshire, UK) and then prepared for mass spectroscopy in 240 the same manner as previously described. 
242 the Campbell laboratory in L1 medium at a salinity of 35 and extracted using the ethyl acetate

243 method, as previously described by Errera et al. (2010). Response to hypoosmotic stress was

244 conducted by diluting a log-stage culture with MilliQ water (Millepore) containing L1 nutrients

245 to a salinity of 27 and comparing the results to a control culture diluted with L1 medium.

\section{3. Results and Discussion}

\section{$247 \quad 3.1$ Cytoxicity}

249 culture. The Delaware culture (DE\#1) showed cytotoxicity in four fractions. The Delaware

250 culture (DE \#2) showed biological activity in five fractions. These fractions all came off during

251 minute 32 through 37 in the crude sample fractionation suggesting these are fairly non-polar

252 compounds. All toxic fractions were further separated using HPLC and were tested in a second

253 cytotoxicity assay. This second assay showed significant cytotoxic activity in four subfractions.

\section{$254 \quad 3.2$ LC-MS}

255 The biologically active DE fractions were analyzed using low resolution mass

256 spectrometry and showed a mass of 896.1, similar to the mass for $\mathrm{PbTx}-2$ (895.4). There was

257 also the presence of the mass 877.4, which is consistent with the daughter ion of $\mathrm{PbTx}-2$ and is

258 attributable to the loss of water (18 amu). This resulted in all of the 896.1 mass containing

259 fractions being chosen for further purification and characterization using NMR. Similar masses

260 were observed in DE \#2 
The New Zealand cultures (NZ\#1 and NZ\#2) showed cytotoxicity in five fractions and

262 twelve fractions respectively. The NZ \#1 fractions showing bioactivity were analyzed using low

263 resolution mass spectrometer. The results of these experiments showed a mass of 896.1 for five

264 fractions. There was also the presence of the mass 877.4, which again is the loss of 18 amu

$265\left(\mathrm{H}_{2} \mathrm{O}\right)$ and is also very characteristic of PbTx-2. The 896.1 mass was also observed in the NZ \#2

266 culture in numerous fractions. Due to the results from the DE culture suggesting that the 896.1

267 mass was $\mathrm{PbTx}-2$, fractions containing this mass were selected for further purification. The

268 purified compounds were then subjected to high resolution mass spectroscopy and NMR

269 analysis.

270

High resolution mass spectrometry was done on three samples (30-8 (NZ\#1), 38-3 (NZ

271 \#2), and 37-2-1 (DE \#1)). Sample nomenclature signifies the $\mathrm{N}^{\text {th }}$ fraction and the $\mathrm{N}^{\text {th }}$ peak

272 collected during purification; ex: $30-8$ signifies the $30^{\text {th }}$ fraction and the $8^{\text {th }}$ peak collected during

273 purification. All three of the samples showed the exact same $\mathrm{m} / \mathrm{z}$ value of 895.48383 and a

274 molecular formula of $\mathrm{C}_{50} \mathrm{H}_{71} \mathrm{O}_{14}$, which match the high resolution $\mathrm{m} / \mathrm{z}$ value and molecular

275 formula of PbTx-2. The library monoisotopic mass for PbTx-2 was declared as 894.476563 Da

276 and our compound showed the monoisotopic mass of $894.476557 \mathrm{Da}$. There is only one other

277 compound in the library with a mass similar and it is that of (10'E,14'E, 16'E)-6-sec-Butyl-24'-

278 hydroxy-5,11',13',22'-tetramethyl-2',21'-dioxo-5,6-dihydrospiro[pyran-2,6'-

$279[3,7,19]$ trioxatetracyclo[15.6.1.1 $\left.1^{4,8} \cdot 0^{20,24}\right]$ pentacosa[10,14,16,22]tetraen]-12'-yl 2,6-di

$280 \& \#$ AA;deoxy-4-O-[(5E)-4-methoxy-6-methyl-5-(2-oxoethylidene)tetrahydro-2H-pyran-2-yl]-3-

281 O-methylhexopyranoside, which will not have a similar ${ }^{1} \mathrm{H}$ NMR spectrum.

282 The results from the DE experiment showed the 895.4/895.4 mass, the ion extraction

283 mass for PbTx-2, in the DE sample to have a retention time of 11.70 minutes. This value, when 
284 compared to the retention time collected from the $\mathrm{PbTx}-2$ standard spectrum was consistent for

285 the known brevetoxin. The results from the NZ experiment showed the 895.4/895.4 mass in the

$286 \mathrm{NZ} \# 1$ sample to have a retention time of 9.02 minutes and for $\mathrm{NZ} \# 2,8.99$ minutes. This value,

287 when compared to the retention time collected from the PbTx-2 standard spectrum, 9.03 minutes,

288 was consistent for the known brevetoxin. Further support that the isolate was $\mathrm{PbTx}-2$ was offered

289 by spiking pure isolate samples with a $\mathrm{PbTx}-2$ standard. Complete overlap between the signals

290 was observed conclusively supporting the compound isolated from the DE and NZ strain was

291 PbTx-2.

292

Using the MRM method described above the NZ strain had a value of 5.48 and $8.49 \mathrm{fg}$

293 cell $^{-1}$, while the DE strain had a much lower concentration of .13 and $.263 \mathrm{fg} \mathrm{cell}^{-1}$. Ranges

294 reported for cultures grown in the Campbell laboratory was 2-9 $\mathrm{fg}$ cell ${ }^{-1}$ with the average

295 brevetoxin production average of $5 \mathrm{fg} \mathrm{cell}^{-1}$. After hypoosmotic stress, toxin production

296 increased 2- to 3-fold over control cultures.

297

Raw culture samples and $.001 \mathrm{~nm}$ concentration of brevetoxin standards were taken and

298 column retention times of specific peaks were compared. The presence of a mass of 895.4 and

299877.7 was observed in the raw samples. The retention time of the compound suspected as PbTx-

3002 from the raw samples showed strong correlation to that observed for the brevetoxin standard

301 (NZ: 9.48 mins and 9.49 mins respectively; DE: 9.35 mins and 9.36 mins respectively).

\section{$302 \quad 3.3{ }^{1}$ H NMR}

303 The structure of the compounds isolated from the New Zealand strain with masses

304 indicative of $\mathrm{PbTx}-2(.268 \mathrm{mg}$ isolated from $\mathrm{NZ} \# 1$ and $.509 \mathrm{mg}$ isolated from NZ \#2) were

305 determined using ${ }^{1} \mathrm{H}$ NMR spectroscopy. Comparison of the H-NMR spectrum from the NZ 
306 unknown and the spectrum of a PbTx-2 standard showed strong overlap (Figure 2). The peaks 1-

3074 on the spectrum showed signals that correlated well with PbTx-2. Peak 1 correlates to the

308 aldehyde proton, peaks 2 and 3 correlate to the exomethylene protons and peak 4 is a

309 combination of the protons on the unsaturated bonds in the A and $\mathrm{H}$-rings.

310 Figure 2: NMR spectra and correlating PbTx-2 molecule.

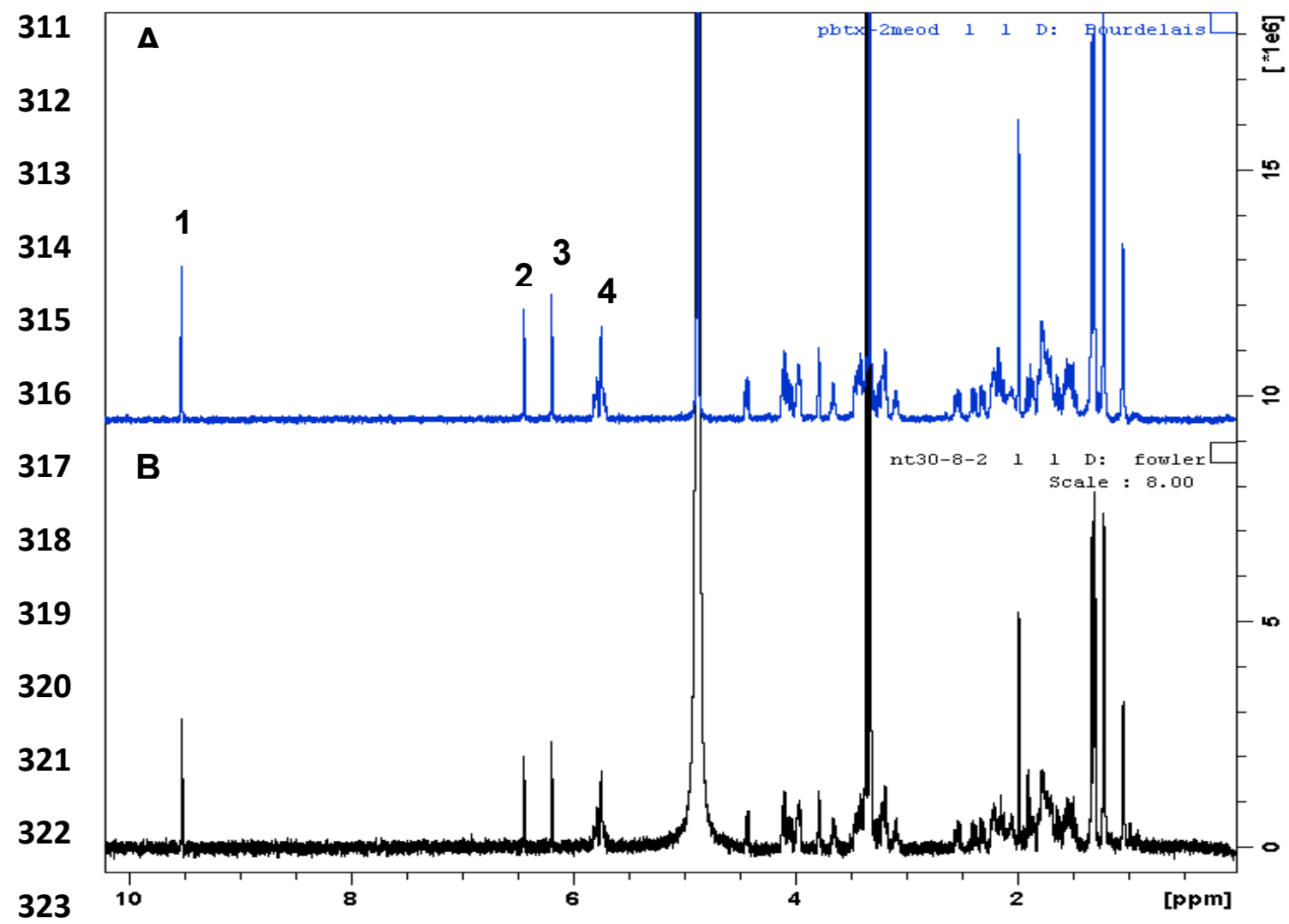




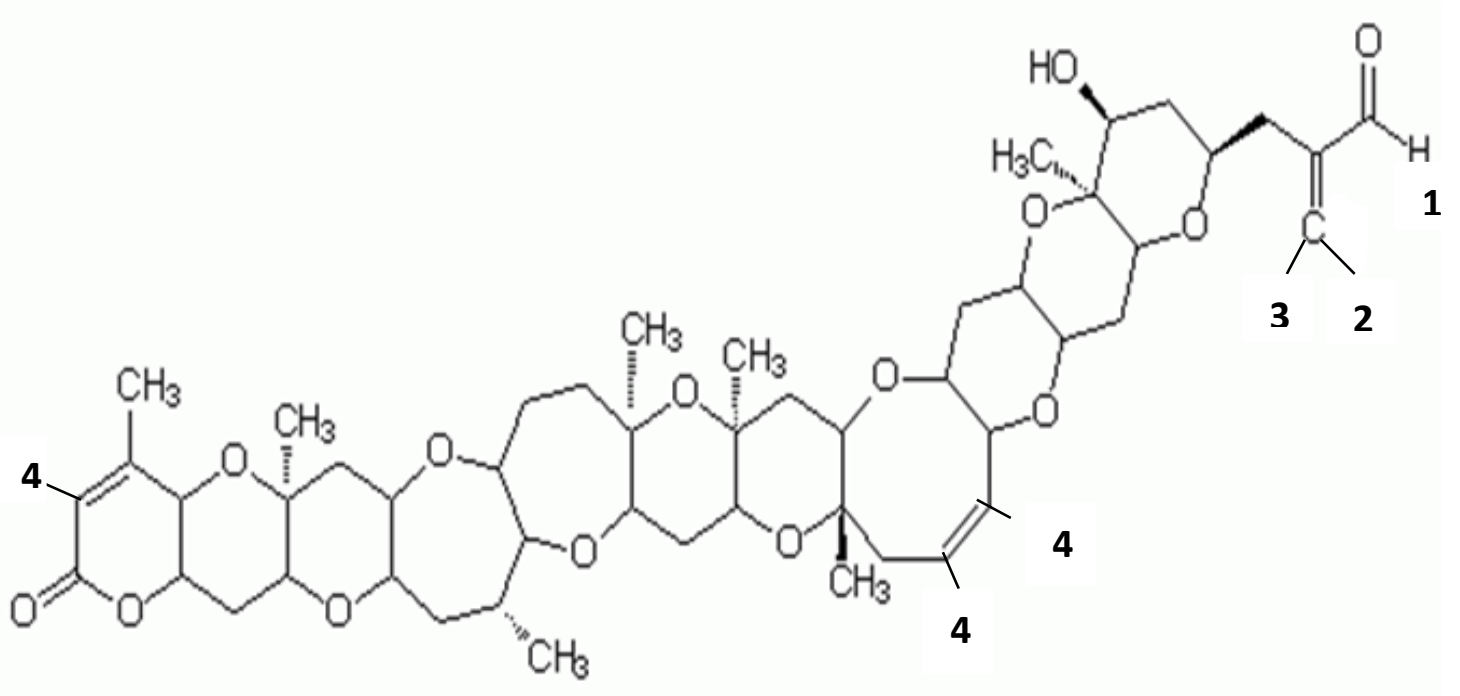

326 Fig. 2: NMR spectrum above shows critical correlating peaks that are identified on the PbTx-2 molecule.

$327 \quad 3.4$ Discussion

$\mathrm{PbTx}-2$ is a known neurotoxin produced by Karenia brevis, but previously not known to

329 be produced by K. papilionacea. Brevetoxins are known to cause massive fish kills and marine 330 mammal mortality in Florida coastal waters as well as neurotoxic effects in humans (Baden et al.

331 1979, Poli et al. 2000, Wu et al. 1988, McFarren et al. 1965, Hughes et al. 1976, Sakamoto et al. 332 1987).

333 The results from mass spectrometry and the NMR experiments suggest that Karenia 334 papilionacea produces the neurotoxin $\mathrm{PbTx}-2$. When compared to K. brevis, K. papilionacea

335 does not produce as much $\mathrm{PbTx}-2$ on a per cell basis. Karenia papilionacea was believed to 336 produce brevetoxin due to low positive ELISA tests (Naar et al. 2002) but it was never

337 confirmed. The presence of PbTx-2 that has been observed in New Zealand without the presence 338 of $K$. brevis can now be explained by the production of this toxin by K. papilionacea. In

339 Delaware, brevetoxins have been detected and have been contributed to the presence of a 
340 Chattonella species that has been shown to also produce PbTx-2 (Bourdelais et al. 2002). It is

341 possible that $K$. papilionacea could also have been contributing to the brevetoxin concentrations

342 that were observed during that bloom. Additionally, brevetoxin has been observed at times when

343 blooms of Chattonella have not been observed, so it is plausible that $K$. papilionacea produced

344 the brevetoxin.

345 The response of K. papilionacea to hypoosmotic stress is similar to previous observations

346 for K. brevis (Errera \& Campbell 2012). Although the function of brevetoxin in Karenia cells is

347 unknown, the similar increase in brevetoxin production in both of these two species in response

348 to rapid decrease in salinity suggests a common role.

349 The production of brevetoxins by $K$. papilionacea is significant because this species has

350 been shown to bloom in areas with extensive shellfish beds (as is seen in Delaware) and may

351 pose a threat to humans through consumption of contaminated shellfish. The shellfish beds that

352 occur in areas that $K$. papilionacea is endemic, may will need to be monitored for brevetoxin

353 accumulation.

\section{4. Conclusions}

355 With the use of HPLC, cytotoxicity assays, Mass Spectrometry, and NMR, it was

356 determined that the New Zealand and Delaware strains of Karenia papilionacea produce PbTx-

357 2. The New Zealand strain produced the most out of the two at approximately $5 \mathrm{fg} \mathrm{cell}^{-1}$, where

358 the Delaware only produced approximately $0.2 \mathrm{fg}$ cell $^{-1}$. Appropriate monitoring measures for $K$.

359 papilionacea should be undertaken in locations with prominent shellfish industry to prevent

360 consumers from being exposed to potentially toxic of brevetoxin which could lead to Neurotoxic 
Shellfish Poisoning. As a result of this study we now have a better understanding of another

toxic Karenia species, which further supports the notion of Karenia as being a toxic genus.

363

$\underline{\text { Acknowledgements }}$

This work was supported by the U.S. National Science Foundation grant no. IOS 1154734, IOS-1155376, and a grant for the State of North Carolina Marbionic US. We would like to express sincere thanks to Liz Elliott, Susan Niven, and Tanya Hogue of the Baden lab. We would also like to thank Bob York and Sarah Karafas of the Tomas lab and Reagan Errera and McKenzie Daugherty of the Campbell lab.

\section{Literature Cited:}

Baden, D.G., Mende, T.J., Block, R.E., 1979. Two similar toxins isolated from Gymnodinium breve. Toxic Dinoflagellate Blooms. Elsevier, New York, pp. 327-334.

Baden D.G. and T.J. Mende. 1982. Toxicity of two toxins from the Florida red tide marine dinoflagellate, Ptychodiscus brevis. Toxicon. 20, 457-461.

Bourdelais, A.J., Tomas, C.R., Naar, J., Kubanek, J., Baden, D.G. 2002. New fish-killing alga in coastal Delaware produces neurotoxins. Environ. Health Prospect. 110, 465-470.

Bourdelais, A.J., Jacocks, H.M., Wright, J.L.C., Bigwarfe, P.M., Baden, D.G., 2005. A new polyether ladder compound produced by the dinoflagellate Karenia brevis. J. of Nat. Prod. 68, 2-6.

Brand, L.E., Campbell, L., Bresnan, E. 2012. Karenia: The biology and ecology of a toxic genus. Harmful Algae. $14,156-178$.

Chang, F.H., 2011. Toxic effects of three closely-related dinoflagellates, Karenia concordia, K. brevisulcata and K. mikimotoi (Gymnodiniales, Dinophyceae) on other microalgal species. Harmful Algae 10, 181-187.

Chang, F.H., MacKenzie, L., Till, D., Hannah, D., Rhodes, L. 1995. The first toxic shellfish outbreaks and the associated phytoplankton blooms in early 1993 in New Zealand. Harmful Marine Algal Blooms. Lavoisier Intercept Ltd., New York, pp. 145-50.

De Salas, M.E., Bolch, C.J.S. Hallegraeff, G.M. 2004. Karenia asterichroma sp nov (Gymnodiniales, Dinophyceae), a new dinoflagellate species associated with finfish aquaculture mortalities in Tasmania, Australia. Phycologia. 43, 624-631.

Errera, R. M., Bourdelais, A., Drennan, M. A., Dodd, E. B., Henrichs, D. W. \& Campbell, L. 2010. Variation in brevetoxin and brevenal content among clonal cultures of Karenia brevis may influence bloom toxicity. Toxicon. 55, 195-203.

Errera, R. M. \& Campbell, L. 2012. Osmotic stress triggers toxin production by the dinoflagellate Karenia brevis. Proceedings of the National Academy of Sciences of the United States of America. 109, 17723-24.

Gómez, F. 2006. The Dinoflagellate Genera Brachidinium, Asterodinium, Microceratiumand Karenia in the Open SE Pacific Ocean. Algae. 21, 445-452.

Guillard, R.L., Hargraves P.E. 1993 Stichochrysisimmobilis is a diatom, not a chrysophyte. Phycologia. 32, 234263.

Harwood, D.T., Feng, S., Masayuki, S., Holland, P.T. 2014. A sensitive LC-MS/MS assay for brevisulcenal and brevisulcatic acid toxins produced by the dinoflagellate Karenia brevisulcata. Toxicon, 84, 19-27.

Haywood, A., Mackenzie, I., garthwaite, I., Towers, N. 1996. Gymnodinium breve 'look-alikes': three Gymnodinium isolates from New Zealand. Harmful and Toxic Algal Blooms, pp. 227-230. 
Haywood, A.J., Steidinger, K.A., Truby, E.W., Bergquist, P.R., Bergquist, P.L., Adamson, J. \& Mackenzie, L. 2004. Comparative morphology and molecular phylogenetic analysis of three new species of the genus Karenia (Dinophyceae) from New Zealand. J. Phycol. 40, 165-179.

Heil, C. A. \& Steidinger, K. A. 2009. Monitoring, management, and mitigation of Karenia blooms in the eastern Gulf of Mexico. Harmful Algae. 8, 611-617.

Holland, P.T., Shi, F., Satake, M., Hamamoto, Y., Ito, E., Beuzenberg, V., McNabb, P., Munday, R., Briggs, L., Truman, P., Gooneratne, R., Edwards, P., Pascal, S.M. 2012. Novel toxins produced by the dinoflagellate Karenia brevisulcata. Harmful Algae. 13, 47-57.

Hughes, J.M. and M.H. Merson. 1976. Fish and Shellfish Poisoning. N Engl J Med. 295, 1117-1120.

Landsberg, J.H. 2002. The effects of harmful algal blooms on aquatic organisms. Rev. Fish. Sci. 10, 113-390.

Lin Y.Y., Risk, M.A., Ray, S.M., Van Engen. D., Clardy, J., Golik, J., James, J.C., Nakanishi, K. 1981. Isolation and structure of brevetoxin B from the "red tide" dinoflagellate Ptychodiscus brevis. JACS; 103, 6773-6775.

Loeblich, A.R. 1975. A seawater medium for dinoflagellates and the nutrition of C. niei. J Phycol. 11, 80-86.

Mackenzie, A.L., Haywood, A.J., Adamson, J., Truman, P., Till, D., Seki, T., Satake, M., Yasumoto, T. 1996. Gymnodimine contamination of shellfish in New Zealand. In: Yasumoto, T., Oshima, Y., Fukuyo, Y. (Eds.), Harmful and Toxic Algal Blooms. Intergovernmental Oceanographic Commission of UNESCO, pp. 97-100.

McFarren, E.F., Silva, F.J., Tanabe, H., Wilson, W.B., Campbell J.E., Lewis, K.H. 1965. The Occurrence of Ciguatera-like Poison in Oysters, Clams and Gymnodinium Breve Cultures. Toxicon. 3, 111-123.

McNabb, P., Rhodes, L., Adamson, J., Holland, P. 2006. Brevetoxin - an elusive toxin in New Zealand waters. African J. Mar. Sci. 28, 375 -377.

Mooney, B.D., Nichols, P.D., de Salas, M.F., Hallegraeff, G.M. 2007. Lipid, fatty acid and sterol composition of eight species of Kareniaceae (Dinophyta): chemotax-onomy and putative lipid phycotoxins. J. Phycol. 43, 101-111.

Naar, J., Bourdelais, A., Tomas, C., Kubanek, J., Whitney, P.L., Flewelling, L., Steidinger, K., Lancaster, J., Baden, D.G. 2002. A competitive ELISA to detect brevetoxins from Karenia brevis (formerly Gymnodinium breve) in seawater, shellfish, and mammalian body fluid. Environ. Health Perspect. 110, 179-185.

Poli, M.A., Musser, S.M., Dickey, R.W., Eilers, P.P., Hall, S. 2000. Neurotoxic Shellfish Poisoning and Brevetoxin Metabolites: A Case Study from Florida. Toxicon. 38, 981-993.

Rhodes, I., White, D., Syhre, M., Atkinson, M. 1996. Pseudonitzschia species isolated from New Zealand coastal waters: domoic acid production in vitro and links with shellfish toxicity. Harmful and toxic Algal Blooms, pp. $155-158$.

Sakamoto, Y., Lockey, R.F., Krzanowski, J.J. Jr. 1987. Shellfish and Fish Poisoning Related to the Toxic Dinoflagellates. S. Med J. pp. 866-872.

Satake, M., Shoji, M., Oshima, Y., Naoki, H., Fujita, T., Yasumoto, T. 2002.Gymnocin-A a cytotoxic polyether from notorious red tide dinoflagellate Gymnodinium mikimotoi. Tetrahedron Lett. 43, 5829-5832.

Satake, M., Tanaka, Y., Ishikura, Y., Oshima, Y., Naoki, H., Yasumoto, T. 2005. Gymnocin-B with the Largest Contiguous polyether rings from the red tide dinoflagellate Karenia (formally Gymnodinium) mikimotoi. Tetrahedron Lett. 46, 3537-3540.

Seki, T., Satake, M., Mackenzie, L., Kaspar, H. and Yasumoto, T. 1995. Gymnodimine, a new marine toxin of unprecedented structure isolated from New Zealand oysters and the dinoflagellate, Gymnodinium sp. Tetrahedr. Lett. 36, 7093-7096.

Seki, T., Satake, M., Mackenzie, L., Kaspar, H. and Yasumoto, T. 1996. Gymnodimine, a novel toxic imine isolated from the Foveaux strait oysters and Gymnodinium sp. Harmful and Toxic Algal Blooms. pp. 495-498.

Steidinger, K.A. 1979. Collection, enumeration and identification of free living marine dinoflagellates. In Taylor, F. J. R. \& Seliger, H. H. (Eds.) Toxic Dinoflagellate Blooms. Elsevier Science Publisher, New York, pp. 435442.

Tatters, A.O., Muhlstein, H.J., Tomas, C.R. 2010. The hemolytic activity of Karenia selliformis and two clones of Karenia brevis throughout a growth cycle. J. App. Phycol. 22, 435-442.

Truxal, L., Bourdelais, A.J., Jacocks, H., Abraham, W.M., Baden, D.G. 2010. Characterization of Tamulamides A and B, Polyethers Isolated from the Marine Dinoflagellate Karenia brevis. J. Nat. Prod. 73, 536-540.

Wu, C.H. and T. Narahashi. 1988. Mechanism of Action of Novel Marine Neurotoxins in Ion Channels. Annu Rev Pharmacol Toxicol. 28, 141-161. 